
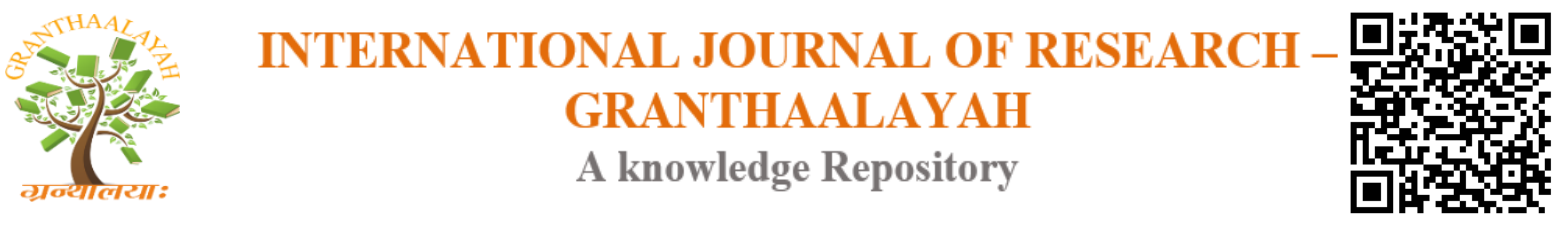

Social

\title{
PARENTAL PERCEPTIONS ABOUT THE EFFECT OF DANCE ACTIVITIES ON THE MOOD AND EMOTIONS OF ADOLESCENTS
}

\author{
Lemonia Darginidou ${ }^{* 1}$, Dimitris Goulimaris ${ }^{2}$, Vassiliki Derri ${ }^{3}$, Giorgos Kosta 4 \\ *1, 2,3,4 Department of Physical Education \& Sports Sciences, Democritus University of Thrace, \\ Greece
}

\begin{abstract}
The aim of this study is to investigate whether parents' perceptions on the emotions and moods of their children are influenced by the children's participating in traditional dance activities. The sample of the research consisted of 280 parents of adolescents aged 12-13. There were three experimental groups: a) "Control group", b) "Experimental group 1" and c) "Experimental group 2". The measurements was carried out with the KIDSCREEN-52 Scale (Ravens-Sieberer et al., 2007). The dimension used was "Mood and emotions", which includes 7 questions. There were three measurements. The results of the research showed that the parents' perceptions concerning the factor "mood and emotions" for the quality of life of their children were differentiated among the groups according to the measurements. According to the parents' perceptions, their adolescent children's moods and emotions were improved after participating regularly in extracurricular Greek dance activities organized by nonprofit private societies. In conclusion, parents acknowledge that their children's participating in dance activities in nonprofit societies improved their general mood and developed their positive emotions, which is quite helpful for adolescents to overcome the emotional disturbance of this age.
\end{abstract}

Keywords: Dancing Activities; Mood and Emotions; Adolescents.

Cite This Article: Lemonia Darginidou, Dimitris Goulimaris, Vassiliki Derri, and Giorgos Kosta. (2018). "PARENTAL PERCEPTIONS ABOUT THE EFFECT OF DANCE ACTIVITIES ON THE MOOD AND EMOTIONS OF ADOLESCENTS." International Journal of Research - Granthaalayah, 6(12), 151-158. https://doi.org/10.29121/granthaalayah.v6.i12.2018.1103.

\section{Introduction}

As children grow up to become adolescents, they develop more advanced skills, so as to understand, express and regulate emotions and adapt themselves in an increasingly complicated world. Thus, they must be equipped with an organized sum of reactions and thoughts in order to be able to comprehend their emotions (Blakemore \& Choudhury, 2006; Saarni, 1999; Steinberg, 2005), since adolescence is a period of increased emotional vulnerability (Dahl, 2001; Steinberg, 2005). 
The emotions and moods which are perceived by teenagers during their adolescence constitute part of a subjective well-being and an influential factor for their quality of life. Adolescents are believed to have a good quality of life, when they experience a minimum of negative emotions. Negative emotions include depressive and stressful emotions and moods which are connected with a subjective sense of painfulness, such as loneliness, sorrow, insufficiency or withdrawal from life (Toundas et all, 2006). The negative emotions which derive from anxiety and stress confrontation are related to a psycho-pathological behaviour that has been studied thoroughly (Fredricksoll, 2001; Frydenberg, 1997).

It is known that positive emotions are indispensible for the human behaviour to adapt to the environment. Furthermore, they contribute to visualizing targets, resolving problems, protecting health and guiding group behaviours. Bandura's theory (1977) claims that people's perceptions on their abilities increase, after participating in physical exercises, which consequently leads to an increased self confidence and positive mood.

Parents play an important role in the lives of children and adolescents (Ross, Zeller, Srisaeng, Yimmee, Sawatphanit, \& Somchid, 2006). The relationship between parents and children and the degree to which parents accept and appreciate their children's emotions constitutes an important part for the children's quality of life (Thompson, 1994). A good relationship is characterized by a positive and pleasant interaction, acceptance (Cohn, Patterson, \& Christopoulous, 1991; Pettit \& Mize, 1993; Putallaz, 1987) and response to mutual emotions (Harrist, Pettit, Dodge, \& Bates, 1994; Pettit, Harrist, Bates, \& Dodge, 1991; Pettit \& Harrist, 1993). Adolescents' emotional development depends on their relationship with their parents (Hightower, 1990; Engels, Finkenauer, Meeus, \& Dekovic, 2001). The way this relationship is self-perceived by parents and children alike enhances the self-esteem of both parts and creates positive results for both the relationship itself and the adolescents' social behaviour and school performance (Demo, Small, \& Savin-Williams, 1987).

There are current researches investigating the way parents perceive various factors of their children's quality of life, in relation to health (Tountas et al., 2006). These researches point out the positive influences of such perceptions, especially concerning children who belong to high risk groups and present developmental incapability or symptoms of fear, depression and aggressiveness (Lau, Chow, \& Lo, 2006).

In a study by Hansen, Larson and Dworkin (2003), it is supported that, during their recreational activities, many adolescents learn to control their anxiety, anger, fear or their emotions after a conflict. In addition, Lerdal, Celius and Pedersen, (2013) claimed that participating in group physical activity programs improves quality of life more effectively than participating in individual ones.

Dance activities constitute a group physical activity (Judge, 2003) and are a form of regular aerobic exercise, which contributes significantly to the general physical and psychological health of adults (Fentem, 1992), given the fact that exercising and practicing intense physical activity in general has important psychological effects on people's quality of life (Theodorakis, 2010). 
Adults' participation in such activities increases the sense of well-being and improves one's mood and perception of entertainment, since dance is a recreational activity (Goulimaris, Filippou, Kottis $\&$ Genti, 2008). Furthermore, practicing traditional dance activities at school may have a positive influence on the attitudes and perceptions of the participants, as well as their intentions to continue practicing (Stivaktaki-Moudatsou, 2011).

The aim of this study is to investigate whether parents' perceptions on the emotions and moods of their children are influenced by the children's participating in traditional dance activities.

\section{Methods}

\section{Participants}

The sample of the research consisted of 280 parents of adolescents aged 12-13. There were three experimental groups: A) "Control group" which included 97 parents whose adolescent children did not take up any physical activity in their free time, B) "Experimental group 1" which included 84 parents whose adolescent children participated for the first time in extra curricular Greek dance programs organized by state schools and C) "Experimental group 2" which included 99 parents whose adolescent children participated for the first time in extracurricular Greek dance activities organized by nonprofit private societies.

\section{Measurement Instruments}

The quality of life measurement was carried out with the KIDSCREEN-52 Scale (Ravens-Sieberer et al., 2007). The dimension used was "Mood and emotions", which includes 7 questions (e.g. "Did you feel sad?"). The answers were given on a 5 degree Likert scale, from "never-always" to "not at all-excessively". The validity and credibility of the scale for the Greek population has been examined and verified in relative researches (Tountas et al., 2006; Giannakopoulos, 2010; Gkoltsiou, 2011; Karasimopoulou, Derri, \& Zervoudaki, 2012).

\section{Procedure}

There were three measurements. The final measurement took place seven months after the initial and the retention measurement took place two weeks after the final. The meetings with the dancers took place in the dance classroom and the courts accordingly. The meetings with the groups took place outside school and during the participants' free time. They were all given instructions, while they were about to fill in the questionnaire. There was also a 5 to 10 minute time for possible questions. The questionnaire was returned during the meetings.

\section{Statistical Analysis}

To analyze the data statistically, the research used descriptive statistics, reliability analysis, one way-ANOVA and analysis of variance for two factors, one of which was repeated.

\section{Results}

\section{Findings}

During the reliability analysis, in every measurement, all Cronbach's $\alpha$ values were acceptable (Table 1). Also, the one way-ANOVA analysis of variance showed that there were not any 
statistically significant differences among the groups, during the initial measurement $\left[\mathrm{F}_{(2,278)}\right.$ $=0.109, \mathrm{p}>0.05]$.

Table 1: Values a, Means, Standard Deviations of the Factor "Mood and Emotions" for the Three Groups, During the Three Measurements

\begin{tabular}{|l|l|l|l|l|}
\hline \multicolumn{2}{|c|}{} & & \multicolumn{3}{|c|}{ MEASUREMENTS } \\
\cline { 3 - 5 } GROUP & INITIAL & FINAL & RETENTION \\
\hline CONTROL & M.O & 4.15 & 4.03 & 4.03 \\
\cline { 2 - 5 } & S.D & 0.54 & 0.38 & 0.45 \\
\hline \multirow{2}{*}{ EXPERIMENTAL 1 } & M.O & 4.12 & 4.14 & 4.14 \\
\cline { 2 - 5 } & S.D & 0.33 & 0.26 & 0.32 \\
\hline EXPERIMENTAL 2 & M.O & 4.06 & 4.20 & 4.19 \\
\cline { 2 - 5 } & S.D & 0.45 & 0.32 & 0.34 \\
\hline TOTAL & M.O & 4.11 & 4.12 & 4.12 \\
\cline { 2 - 5 } & S.D & 0.45 & 0.33 & 0.38 \\
\hline & a Cronbach & 0.75 & 0.79 & 0.76 \\
\hline
\end{tabular}

The analysis of variance for the dependent samples concerning the two factors (group and measurement), one of which was repeated, showed a statistically significant interaction between the two factors $\left[\mathrm{F}_{(4,554)}=7.323, \mathrm{p}<.05\right]$. The interaction analysis for each degree of the independent factor showed a statistically significant influence of the repeated factor "measurement" on the "control group" $\left[\mathrm{F}_{(2,277)}=4.089, \mathrm{p}<.05\right]$ and on the "experimental group 2 " $\left[\mathrm{F}_{(2,277)}=5.761, \mathrm{p}<.05\right]$. The multiple-comparison Bonferroni test showed that were statistically significant differences concerning the "control group" and the "experimental group 2", between the initial and the other two measurements. The observation of the means (Table 1) confirms that for the "control group", the means of the parents' perceptions about the moods and emotions of their children were reduced in the final measurement and remained reduced in the retention measurement. For the "experimental group 2", the means of the parents' perceptions about the moods and emotions of their children increased since the initial measurement and remained increased in the retention measurement (Table 1).

As concerns the differences among the groups, during the final measurement $\left[\mathrm{F}_{(2,277)}=6.709, \mathrm{p}<.05\right]$ and the retention measurement $\left[\mathrm{F}_{(2,277)}=4.768, \mathrm{p}<.05\right]$, there were statistically significant differences. The multiple-comparison Bonferroni test, during the final and the retention measurement, showed statistically significant differences concerning the perceptions of the adolescents" parents of the "control group" and the "experimental group 2". The observation of the means of the parents' perceptions about the moods and emotions of their children during the final measurement showed a higher mean for the parents of the "experimental group 2" (Table 1).

\section{Discussions}

The issue that was investigated was whether the adolescents' participating in traditional dance programs influences their parents' perceptions on their children's emotions and moods, which constitute a factor for the quality of life. 
In general, the adolescents' parents of all three groups perceive that their children are in a very good mood and demonstrate positive emotions. The means of their perceptions varied from 4.11 to 4.12 (Table 1).

The results of the research showed that the parents' perceptions concerning the factor "mood and emotions" for the quality of life of their children were differentiated among the groups according to the measurements. The highest mean appeared in the adolescent group which participated in extracurricular Greek dance activities organized by nonprofit private societies. The parents of this group perceived that there was an improvement in the emotions and moods of their children during the measurements of the investigation. This result is in accordance with the ones of similar investigations. Participating in dance activities provokes an interaction between emotions and movement in which dance influences the mood and the emotional world of the dancers (Foster, 1976). A dance activity gives its participants the chance to communicate with others on a personal and group level, as well as the ability to control their emotions and perceive the emotions of others effectively (Bougiesi, 2011). Dealing with recreational dance activities affects one's physical, spiritual and psychological health (Genti, Goulimaris \& Yfantidou, 2009; Goulimaris, Mavridis, Genti \& Rokka, 2014) and, in addition, is a proof of a high standard of living (Diener, Suh, Lucas \& Smith, 1999). Parents acknowledge that their children's participating in dance activities organized by nonprofit private societies has improved their general mood and developed their positive emotions.

The parents of the adolescent group that did not take up any regular physical activity perceived a reduction in the positive moods and emotions of their children which was connected with the emotional vulnerability of the adolescent period (Dahl, 2001; Steinberg, 2005). The perceptions of the parents of the adolescent group that participated in extra curricular Greek dance programs organized by state schools remained unaltered, probably because these programs were conceived and realized within the framework of the school. Similar results were found in an investigation by Zervoudaki (2011) who studied the quality of life of primary school children and used the same measurement instrument as the present investigation, when applying a health related intervention program entitled "Skills of primary school children".

According to the parents' perceptions, their adolescent children's moods and emotions were improved after participating regularly in extracurricular Greek dance activities organized by nonprofit private societies. These findings are connected with similar ones concerning older people as well as with investigations which studied the effects of dance activities as a means of exercising, in order to reduce depression symptoms (Kaltsatou, Mameletzi, \& Douka, 2010), transitional anxiety and improve the mood of the participants (Papaioannou, Mavrovouniotis \& Argiriadou, 2009). Furthermore, the positive effects of dance activities on children who practiced them in nonprofit private societies can also be explained by their motivation to present these activities in front of an audience and be a part of group of children of various ages who want to fulfill a common purpose. 


\section{Conclusions and Recommendations}

In conclusion, parents acknowledge that their children's participating in dance activities in nonprofit societies improved their general mood and developed their positive emotions, which is quite helpful for adolescents to overcome the emotional disturbance of this age.

\section{Acknowledgements}

It is suggested that the research be extended to include adolescents older than 13 , who also participate in dance activities.

\section{References}

[1] Blakemore, S.J., \& Choudhury, S. (2006). Development of the adolescent brain: implications for executive function and social cognition. Journal of Child Psychology and Psychiatry, 47, 296-312.

[2] Bougiesi, M. (2011). Mental Health and Emotional Intelligence differences among participants in dance and other types of exercise in young and older adults (In Greek). Unpublished doctoral dissertation, University of Thessaly, Greece.

[3] Cohn, D., Patterson, C., \& Christopoulos, C. (1991). The family and children's peer relations. Journal of Social and Personal Relationships, 8, 315-346.

[4] Dahl, R. E. (2001). Affect regulation, brain development, and behavioral/emotional health in adolescence. CNS Spectrums, 6, 60-72.

[5] Demo, D. H., Small, S. A., \& Savin-Williams, R. C. (1987). Family Relations and the Self-Esteem of Adolescents and Their Parents. Journal of Marriage and the Family, 49(4), 705-715.

[6] Diener, E., Suh, E., Lucas, R., \& Smith, H. (1999). Subjective well-being: three decades of progress. Psychological Bulletin, 125, 276-302.

[7] Engels, R. C., Finkenauer, C., Meeus, W., \& Dekovic, M. (2001). Parental attachment and adolescents' emotional adjustment: The associations with social skills and relational competence. Journal of Counselling Psychology, 45(4), 428-439.

[8] Fentem, P.H. (1992). Exercise in prevention of disease. British Journal of Medical Bulletin, 48(3), 630-650.

[9] Foster, R. (1976). Knowing in My Bones. London.

[10] Fredricksoll, B. L. (2001). The role of positive emotions in positive psychology: The broadenandbuild theory of positive emotions. American Psychologist, 56, 218-26.

[11] Frydenberg, E. (1997). Adolescent coping: Theoretical and research perspectives. London: Routledge.

[12] Genti, M., Goulimaris, D. \& Yfantidou, G. (2009).The Psychological Mood of Adult Participants in Aerobics, Greek Traditional Dancing and Muscle Strengthening Programs. International Journal of Sport Management, Recreation \& Tourism, 4, 40-51.

[13] Giannakopoulos, G. (2010). The early detection of emotional and behavioral problems of adolescents in Greek school: Example of Capability and Difficulties questionnaire (in Greek). Unp. Ph. D. University of Athens.

[14] Gkoltsiou, K. (2009). Study quality of life related to health on a national representative sample of students a'levels of public education (in Greek). Unp. Ph. D., University of Athens.

[15] Goulimaris D., Fillipou F., Kottis I. \& Genti M. (2008). The Perceived Constraints Participation Factors in Greek Traditional Dances (In Greek). Science of Dance,2,16-30. Retrieved from http://elepex.gr/volumes/vol2/Goulimaris_paper.pdf

[16] Goulimaris, D., Mavridis, G., Genti, M. \& Rokka S. (2014). Relationships between basic psychological needs and psychological well-being in recreational dance activities. Journal of Physical Education and Sport, 14(2), 277-284. 
[17] Hansen, D.M., Larson, R.W., \& Dworkin, J.B. (2003). What adolescents learn in organized youth activities: a survey of self-reported developmental experiences? Journal of Research on Adolescence, 13, 25-55.

[18] Harrist, A, W., Pettit, G. S., Dodge, F, A., \& Bates, J. E. (1994). Dyadic synchrony in mother-child interaction: Relation with children's subsequent kindergarten adjustment. Family Relations, 43, 417-424.

[19] Hightower, E. (1990). Adolescent interpersonal and familial precursors of positive mental health at midlife. Journal of Youth \& Adolescence, 19(3), 257-275.

[20] Judge, J.O. (2003). Balance training to maintain mobility and prevent disability. American Journal of Preventive Medicine, 25, 150-156.

[21] Kaltsatou, A., Mameletzi, D. \& Douka, S. (2010). Physical and psychological benefits of a 24week traditional dance program in breast cancer survivors. Journal of Bodywork \& Movement Therapies, 20, 1-6.

[22] Karasimopoulou, S., Derri, B. \& Zervoudakı, E. (2012). Children's perceptions about their healthrelated quality of life: effects of a health education-social skills program. Health education research,27(5), 780-793.

[23] Lau, K. M., Chow, S. M. K. \& Lo, S. K. (2006) Parents' perception of the quality of life of preschool children at risk or having developmental disabilities. Quality of Life Research, 75(7), 1133-1141.

[24] Lerdal, A., Celius, E.H., \& Pedersen, G. (2013). Prescribed exercise: a prospective study of healthrelated quality of life and physical fitness among participants in an officially sponsored municipal physical training program. Journal of Physical Activity \& Health, 10, 1016-1023.

[25] Papaioannou, C., Argiriadou, E., \& Mavrobouniotis, F. (2009). The effect of Greek traditional dances on elderly women's well-being, Woman \& Sports, 7, 25- 38.

[26] Pettit, G. S., \& Harrist, A. W. (1993). Children's possessive and socially unsaved playground behavior with peers: Origins in early family relations. In C. H. Hart (Eds), Children on playgrounds: Research perspectives and applications, (pp. 240-270). Albany: State University of New York Press.

[27] Pettit, G. S., \& Mize, J. (1993). Substance and style: Understanding the ways in which parents teach children about social relationships. In S. Duck (Eds), Understanding relationship processes (pp. 118-151). Learning about relationships. Newbury Park, CA: Sage.

[28] Pettit, G. S., Harrist, A. W., Bates, J. E., \& Dodge, K A. (1991). Family interaction, social cognition, and children's subsequent relations with peers at kindergarten. Journal of Social and Personal Relationships, 8, 383-402.

[29] Putallaz, M. (1987). Maternal behavior and children's sociometric status. Chiamo Development, 58, 324-340.

[30] Ravens-Sieberer, U., Auquier, P., Erhart, M., Gosch, A., Rajmil, L., Bruil, J., Power, M., Duer, W., Cloetta, B., Czemy, L., Mazur, J., Czimbalmos, A., Tountas, Y., Hagquist, C., Kilroe, J., \& European Kidscreen Group. (2007). The KIDSCREEN-27 quality of life measure for children and adolescents: psychometric results from a cross-cultural survey in 13 European countries. Quality of Life Research, 16(8), 1347-1356. doi: 10.1007/s11136-007-9240-2

[31] Ross, R., Zeller, R., Srisaeng, P., Yimmee, S., Sawatphanit, W., \& Somchid, S. (2006). SelfEsteem, Parent-Child Interaction, Emotional Support, and Self-Perception among Thai Undergraduate Nursing Students. International Journal of Nursing Education Scholarship, 3(1), 120-126.

[32] Saarni, C. (1999). The development of emotional competence. Odessa: Guilford Press.

[33] Steinberg L. (2005). Cognitive and affective development in adolescence. Trends in Cognitive Sciences. PubMed, 9(2), 69-74.

[34] Stivaktaki-Moydatsou, X. (2011). Organization and implementation of a special cross curricular teaching programme of traditional dances and its impact on the attitudes and perceptions of greek school students in the first year of secondary school (In Greek). Unpublished doctoral dissertation, School of human movement and quality of life, University of Peloponnese, Greece. 
[35] Theodorakis,G.(2010). Practice, wellbeing and quality of life (In Greek), Thessaloniki: Christodoulidis

[36] Thompson, R. A. (1994). Emotion regulation: A theme in search of definition. In N. Fox (Eds.). The Development of emotion regulation: Biological and behavioral considerations. Monographs of the Society for Research in Chiamo Development, 59(2-3), 23-32.

[37] Toundas, G., Tsiantis, J., Dimitrakaki, X., Petanidou, D., Tzavara, X., Dereme,S., Papadopoulou, K., \& Stohikidou, M. (2006). The KIDSCREEN project. Evaluation the quality of life relatıve to health of children and adolescents. (In Greek). Retrieved from http://www.neahygeia.gr/UserFiles/File/MELETH_KIDSCREEN.pdf.

[38] Zervoudaki, E. (2011). Perceptions of Primary school children's parents after the educational program for social efficiencies on dimensions of their health related quality of life (In Greek) Postgraduate dissertation, D.P.E.S.S. Democritus University of Thrace.

\footnotetext{
*Corresponding author.

E-mail address: ldargini@ phyed.duth.gr
} 